\title{
The Selfitis Behavior Scale: An Adaptation Study
}

\author{
Ersun Ciplak, $(\mathrm{PhD})$ \\ Ministry of National Education, Turkey \\ Meral Atici, $(\mathrm{PhD})$ \\ Cukurova University, Turkey
}

Doi:10.19044/ejes.v8no2a29

URL:http://dx.doi.org/10.19044/ejes.v8no2a29

Submitted: 02 March 2021

Accepted: 01 April 2021

Published: 30 June 2021
Copyright 2021 Author(s)

Under Creative Commons BY-NC-ND

4.0 OPEN ACCESS

\begin{abstract}
This study aimed to adapt the Selfitis Behavior Scale (SBS) to measure university students' selfitis behavior in Turkey. Within the scope of the study, the SBS was translated from English to Turkish. Data were collected in the validity and reliability studies from four study groups, including 343 university students. According to the confirmatory factor analysis findings, the SBS had good fit indices. As is expected, the criterion-related validity study found moderate- and highlevel positive correlations between the SBS subscales and total scores and the Selfie Attitude Scale (SAS) subscales and total scores. The other criterion-related validity study demonstrated that individuals taking a higher number of selfies than the sum of the scale and subscales scored significantly higher than individuals taking a lower number of selfies. The internal consistency coefficient was calculated to be .92 for the SBS total score, .78 for the Environmental Enhancement Subscale (SBS-EE), .68 for the Social Competition Subscale (SBS-SC), .72 for the AttentionSeeking Subscale (SBS-AS), .84 for the Mood Modification Subscale (SBS-MM), .82 for the SelfConfidence Subscale (SBS-S), and .70 for the Subjective Conformity Subscale (SBS-SCon). The test-retest correlation values found by applying the measurement tool once in four weeks were 77 (SBS), .70 (SBS-EE), .60 (SBS-SC), .82 (SBS-AS), .80 (SBS-MM), .61 (SBS-S), and .61 (SBSSCon), respectively. The mentioned findings demonstrated that the SBS was a valid and reliable measurement tool capable of measuring the selfitis behavior of university students in Turkey.
\end{abstract}

Key Words: Confirmatory Factor Analysis, Reliability, Selfie, Selfitis Behavior Scale, Validity

\section{Introduction}

Technological products considerably influence human life in the digital age, especially those that have become a part of everyday life. Nowadays, people communicate with smartphones, which are the most important among these technological products, and access and share information. Currently, it is very easy to communicate and access information since such a habit 
has been added to the repertoire of human behavior. Therefore, it is not surprising to see people taking selfies almost everywhere. Taking selfies has become a part of everyday life, especially for young people (Senft and Baym, 2015).

In the related literature, taking a selfie is defined as taking a person's self-image (Alblooshi, 2015). Since smartphones both have a camera and easy access to photo editing programs, young people can take selfies, edit selfies, and share them on social media networks with no time and space limits. Recently, scientists have been trying to answer the following question: What makes selfies so attractive to young people? An answer may be that young people take selfies to socialize and become popular (Alfailakawi, 2018; Amurao and Castronuevo, 2016). While this answer is rational, it cannot be sufficiently descriptive on an important issue because that answer does not help experts understand that people are putting themselves in danger when taking selfies. In recent days, news about people injuring themselves while taking selfies has been frequently featured in the media (Dokur, Petekkaya, and Karadag, 2018; Nearly 260 People, 2018). That is why researchers are making intensive efforts to uncover the variables associated with selfie behavior.

Some time ago, there was a fake news story on social media. According to this news, 'selfitis' (selfie addiction) was identified as a psychiatric disorder in the DSM. However, the American Psychological Association (APA) soon denied the claim in the news (APA, n.d.; APA: Taking selfies, 2014; Zhang, 2017). This fake news stated that selfitis was a distinct mental disorder associated with narcissism and obsessive-compulsive disorder (APA, 2018). Although this fake news has been rejected, a number of researchers have indicated that excessive selfietaking may be a psychopathology (Vats, 2015). Safna (2017) reported that selfie addiction might lead to several problems for young people, including accidents, suicide, plastic surgery, skin damage, and loss of self-confidence.

When the relevant literature is reviewed, it is observed that researchers have studied selfietaking behavior using a very broad range of research methods, including qualitative and quantitative ones. In qualitative studies, variables associated with selfie-taking behavior were identified, while quantitative studies investigated the relationships among these variables (AlMenayes, 2015; Balakrishnan and Griffiths, 2017; Boursier, Gioia and Griffiths, 2020a, 2020b; Cedillo and Ocampo, 2016; Charoensukmongkol, 2016; Edwards, 2017; Hingerton, 2016; Marcial, 2015; Mullai, Macaj and Kotherja, 2017; Nagalingam and Arumugam, 2015; Nagalingam, Arumugam, and Thenniz Preethy, 2019; Tiggemann, Anderberg and Brown, 2020). For example, in these studies, the relationships between selfie-taking and the variables of selfesteem, narcissism, attention-seeking, loneliness, egocentrism, interpersonal approval, and problematic internet usage were investigated. There are also studies on selfie-taking behavior that focus on establishing models and scale development (Balakrishnan and Griffiths, 2017; Charoensukmongkol, 2016; Solanki, 2017). The first one of these studies was conducted by Charoensukmongkol (2016). In this model, the researcher examined the relationships between selfie-taking behavior and the variables of attention-seeking, egocentrism, loneliness, and narcissism. As a result of the study, Charoensukmongkol found that these variables were associated with selfies. On the other hand, Solanki (2017) developed a scale including 47questions. In addition to narcissistic personality disorder, Solanki's scale helps researchers determine the association of selfie behavior with various mental health disorders, such as low self-esteem and body perception disorder. Another scale development study was carried out by Balakrishnan and Griffiths (2017). On this scale, self-taking behavior is considered in associationwith six latent variables, namely environmental enhancement, social competition, attention- seeking, mood modification, self-confidence, and subjective conformity. 
To date, researchers in Turkey have shown less interest in studying selfie-taking behavior. Therefore, there are few quantitative and qualitative studies on selfie addiction in Turkey. However, a scale development study aims to assess high school students' selfie attitude, as the literature shows (Ciplak and Cam, 2019). Since the Selfie Attitude Scale (SAS) is not such a measurement tool to identify selfie addiction and is also intended only for high school students, it has limitations in terms of the population that can be used and identifying addiction. Therefore, an absence of such a scale may hinder/make it impossible to study selfie-taking behavior for researchers in Turkey.

From this point of view, it is thought that the adaptation of the Selfitis Behavior Scale introduced by Balakrishnan and Griffiths (2017) to Turkish will meet a significant need. Depending on its significance and logical background, this study aimed to adapt the Selfitis Behavior Scale (SBS) to Turkish. To this end, the SBS was first translated into Turkish, and then the psychometric properties of the scale were examined and determined.

\section{Method \\ Participants}

The research included four study groups, comprising 343 students attending universities in different parts of Turkey during the 2020-2021 academic year. The first study group consisted of 37 university students (27 females: $73.0 \%, 10$ males: $27.0 \%$ ) and produced data for testing the language reliability of the scale. The confirmatory factor analysis study was carried out using the data obtained from another study group consisting of 246 university students (195 females: 79.3\%, 51 males: $20.7 \%$ ). In the criterion-related validity (similar scale validity) study, the third study group consisted of thirty (25 females: $83.3 \%, 5$ males: $16.7 \%$ ) university students. The fourth study group, in which the test-retest study was performed, included 30 university students (23 females: 76.7\%; 7 males: $23.3 \%$ ). Table 1 contains the detailed descriptive characteristics of the university students in the study groups.

Table 1: Descriptive characteristics of the participants

\begin{tabular}{lllllll}
\hline & Gender & & & Grade level & \\
& & $\mathrm{f}$ & $\%$ & & $\mathrm{f}$ & $\%$ \\
\hline Sample 1 & Female & 27 & 73.0 & First & - & - \\
N: 37 & Male & 10 & 27.0 & Second & - & - \\
& & & & Third & - & - \\
& & & & Fourth & 37 & 100.0 \\
\hline Sample 2 & Female & 195 & 79.3 & First & 75 & 30.5 \\
N: 246 & Male & 51 & 20.7 & Second & 41 & 16.7 \\
& & & & Third & 55 & 22.4 \\
& & & & Fourth & 75 & 30.5 \\
\hline Sample 3 & Female & 25 & 83.3 & First & 5 & 16.7 \\
N: 30 & Male & 5 & 16.7 & Second & 21 & 70.0 \\
& & & & Third & 4 & 13.3 \\
\cline { 1 - 2 } & & & & Fourth & - & - \\
\hline
\end{tabular}




\begin{tabular}{|c|c|c|c|c|c|c|}
\hline \multirow[t]{3}{*}{$\mathrm{N}: 30$} & \multirow[t]{3}{*}{ Male } & \multirow[t]{3}{*}{7} & \multirow[t]{3}{*}{23.3} & Second & 10 & 33.3 \\
\hline & & & & Third & 7 & 23.3 \\
\hline & & & & Fourth & 7 & 23.3 \\
\hline
\end{tabular}

\section{Data Collection Tools}

Selfitis Behavior Scale (SBS): The aim of the SBS, established by Balakrishnan and Griffiths (2017), is to identify selfitis behavior in university students. The scale was developed with 400 university students. The scale comprises 20 items having five-point Likert-type response options. The SBS $(\alpha: .88)$ consists of six factors including Environmental Enhancement (SBS-EE, $\alpha: .84$ ), Social Competition (SBS-SC, $\alpha: .83$ ), Attention-Seeking (SBS-AS, $\alpha: .81$ ), Mood Modification (SBS-MM, $\alpha: .82$ ), Self-confidence (SBS-S, $\alpha: .79$ ), and Subjective Conformity (SBS-SCon, $\alpha:$.75). The factor loads of the scale items, in which $70.69 \%$ of the total variance is explained by six factors, change in the range of $.71-.86$. The SBS has the following fit indices: $X^{2} /$ df: 1.38; RMSEA: .031; GFI: .95; AGFI. .93; NFI: .94; CFI: .98. During the process of adapting the SBS to Turkish, Janarthanan Balakrishnan and Mark D. Griffiths were first contacted through e-mail, and the permission required to adapt the scale was acquired. After consent was obtained, three lecturers, proficient in English, translated the scale independently from the source language into the target language, i.e. from English into Turkish. As a result of the comparison of the translations, the Turkish statements representing every item in the best way were revealed. Afterward, the back-translation method was implemented with the aim of testing the Turkish version's equivalence with the original scale. To this end, three faculty members, proficient in Turkish and English, translated the Turkish version to English in an independent way, and therefore, the scale's back translation was acquired. Following the determination of linguistic equivalence, the scale's Turkish version was acquired. The correlation between the scale's Turkish version and the back translation of the scale was computed. The findings obtained through the SBS's linguistic equivalence research demonstrated that the correlation between the Turkish version and the original form was .98 for the overall scale.

Selfie Attitude Scale (SAS): The SAS, developed by Ciplak and Cam (2019), aims to determine selfie attitude in high school students. The scale was developed with 697 high school students. The scale comprises 28 items having five-point Likert-type response options. The SAS ( $\alpha:$.94) consists of two factors, including Positive Experiences to Selfie (SAS-PES, $\alpha: .91$ ) and Negative Experiences on Prevention (SAS-NEP, $\alpha:$.93). The factor loads of the scale items, in which $46.09 \%$ of the total variance is explained by two factors, change in the range of $.44-.78$. The SAS has the following fit indices: $X^{2} / \mathrm{df}$ : 1.46; p: .00; RMSEA: .065; SRMR: .080; NFI: .92; NNFI: .97; CFI: .98. As part of this study, the following values were obtained as a result of the CFA conducted to test the validity of the SAS structure on university students: $X^{2} / \mathrm{df}: 2.99 ; \mathrm{p}: .00$; RMSEA: .090; RMR: .078; NFI: .90; NNFI: .93, and CFI: .93. The factor loads of the scale items varied between .38 and .82 . The Cronbach's alpha values of the SAS are .91 (SAS-PES: .90 and SAS-NEP: .81).

\section{Data Collection}

Data were collected between September 2020 and December 2020. The data were collected using Google Forms under the COVID-19 pandemic conditions. The SBS and SAS were 
transferred to the internet environment, and announcements were made to volunteer participants. Data collection, lasting for about 20 minutes, was performed on a voluntary basis.

\section{Data Analysis}

Within the scope of the current research, the data acquired from the measurement tools were primarily reviewed, the scales responded incorrectly were identified, and SPSS 22.0 and LISREL 8.70 statistical package programs were utilized for the analysis of the data transferred to the digital environment. In the data analysis, the independent samples t-test, confirmatory factor analysis (CFA), and Pearson's correlation coefficient were employed. While interpreting the findings, the level of .05 was considered significant.

\section{Ethics}

The university research ethics committee of the second author approved the research. Informed consent on participation in the research was acquired from all participants.

\section{Results}

\section{Confirmatory Factor Analysis (CFA)}

According to the CFA performed with the data obtained from 246 university students, the factor loads of 20 items of the SBS ranged from .60 to .88, and the error variances ranged from .23 to .66. Upon reviewing the fit indices, the values of $X^{2} / \mathrm{df}: 2.16$, p: .00, RMSEA: .069, SRMR: .059 , NFI: .96, NNFI: .97, CFI: .97, and GFI: .88 were found. The analysis demonstrated that the $X^{2} / \mathrm{df}$, NFI, NNFI, and CFI values of the SBS exhibited excellent compatibility, whereas its RMSEA and SRMR values exhibited good compatibility. The t-values acquired as a result of the CFA for the items in the SBS ranged from 9.38 to $16.97(\mathrm{p}<.05)$. However, since the GFI value was not found within acceptable limits, the modification suggestions were reviewed, and a decision on combining the error variances of item 13 and item 19 of the same factor (the first factor) was taken.

The findings acquired following the modification showed that the scale's factor loads ranged from .46 to .88 , and the error variances ranged from .23 to .79 . Upon examining the fit indices, the values of $X^{2} / \mathrm{df}: 1.62$, p: .00, RMSEA: .050, SRMR: .049, NFI: .97, NNFI: .98, CFI: .99, and GFI: .91 were acquired. The t-values obtained as a result of the CFA for the SBS items ranged from 6.93 to 16.99 ( $\mathrm{p}<.05$ ). The analysis demonstrated that the $X^{2} / \mathrm{df}, \mathrm{RMSEA}, \mathrm{SRMR}$, NFI, NNFI, and CFI values of the SBS exhibited excellent compatibility, whereas its GFI value showed good compatibility. Therefore, when the analysis of all the values is conducted together, it is possible to say that the six-factor structure of the SBS showed compatibility (See Figure 1). 


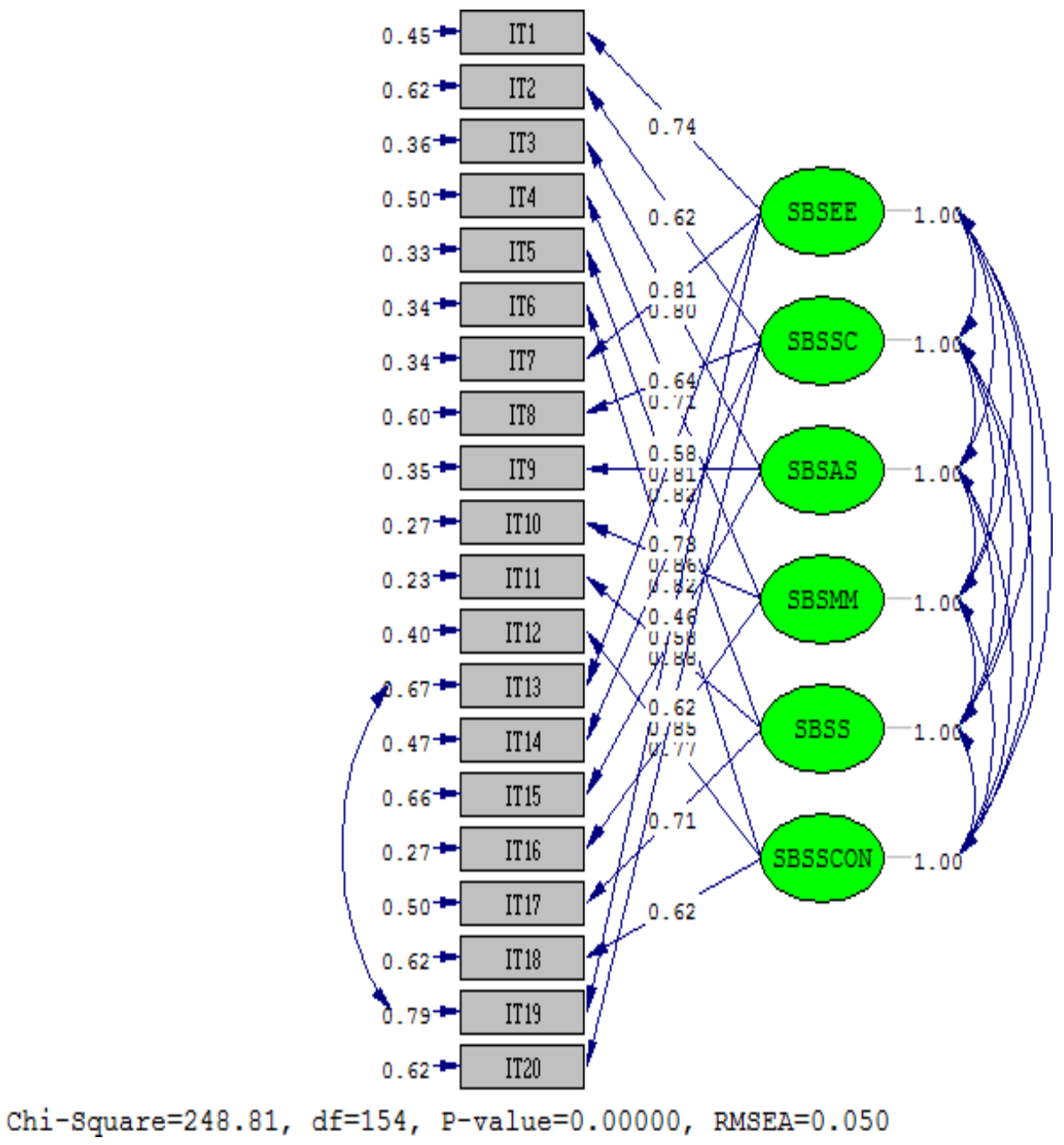

Figure 1: The SBS' path diagram

\section{Second-Order Confirmatory Factor Analysis}

The second-order CFA was also performed to determine whether the six-factor structure of the SBS predicted a single variable. As a result, the factor loads of 20 items of the SBS were observed to range from .60 to .86 , and the error variances ranged from .27 to .65 . Upon reviewing the fit indices, $X^{2} / \mathrm{df}: 3.03$, p: .00, RMSEA: .091, SRMR: .069, NFI: .94, NNFI: .95, CFI: .96, and GFI: .83 values were obtained. As a result of the CFI analysis, the CFI and NNFI values of the SBS values exhibited excellent compatibility, whereas its $X^{2} / \mathrm{df}$, SRMR, and NFI values exhibited good compatibility. The RMSEA and GFI values of the SBS were not at a good level. The t-values found as a result of the CFA for the items in the SBS ranged from 7.84 to 15.20 ( $p<.05$ ). However, since the RMSEA and GFI values were not found within acceptable limits, the modification suggestions were reviewed, and a decision on combining the error variances of item 13 and item 19 of the same factor (the first factor) was made.

The findings acquired following the modification showed that the scale's factor loads ranged from .46 to .86 , and the error variances ranged from .27 to .79 . The standardized values between the SBS subscales scores and the SBS total score ranged from .76 to .94. When the fit indices were investigated, the values of $X^{2} / \mathrm{df}: 2.49$, p: .00, RMSEA: .078, SRMR: .060, NFI: .95, 
NNFI: .97, CFI: .97, and GFI: .86 were found. The t-values computed by the CFA for the SBS items ranged from 6.54 to $15.16(\mathrm{p}<.05)$. The analysis showed that the $X^{2} / \mathrm{df}$, NFI, NNFI, and CFI values of the SBS exhibited excellent compatibility, whereas its RMSEA and SRMR values exhibited good compatibility. Despite an increase in the GFI value following the modification, it was not at a good level. Nevertheless, when the analysis of all the values is performed together, it is possible to say that the six-factor structure of the SBS showed compatibility (See Figure 2).

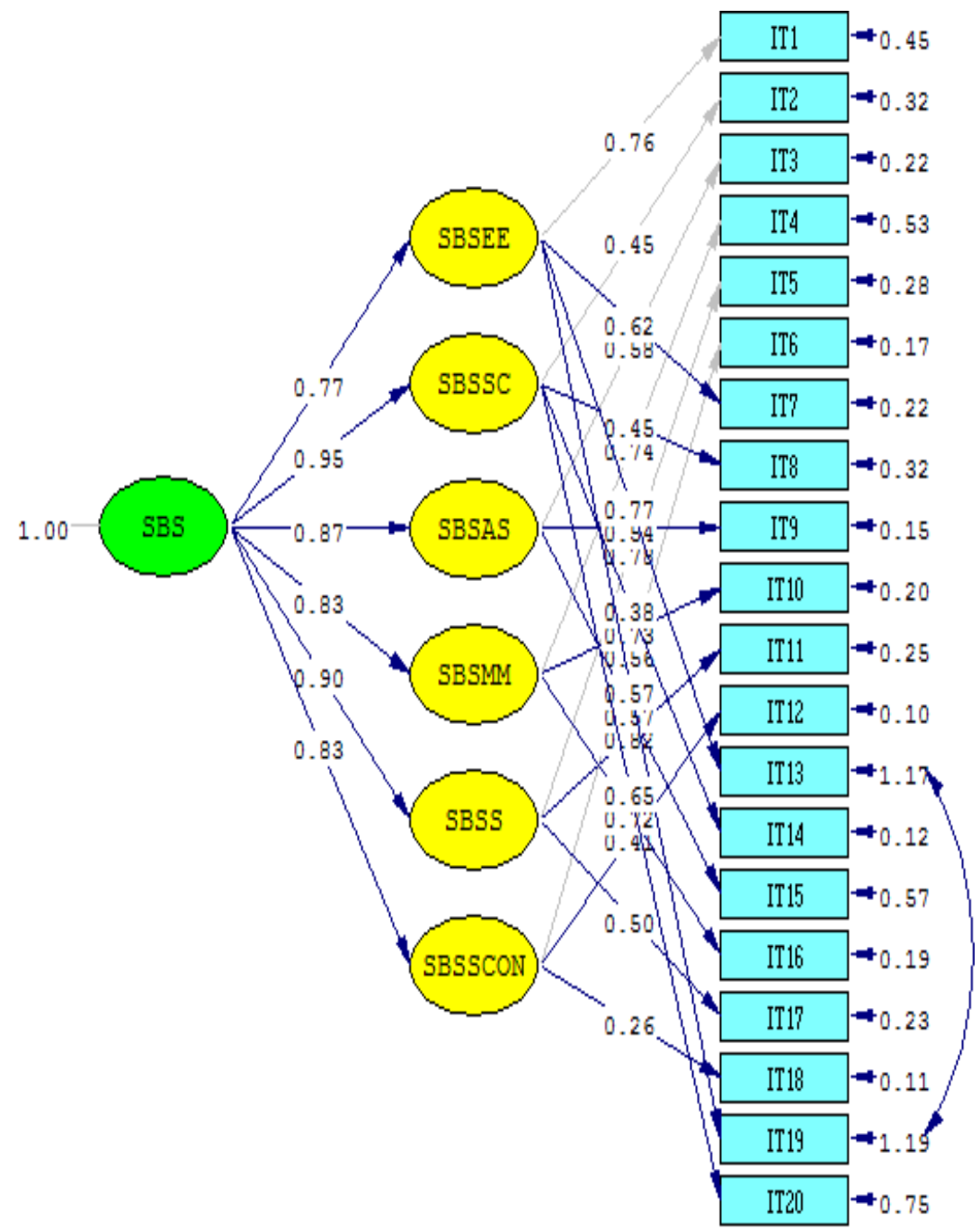

Chi-Square $=406.32, \mathrm{df}=163, \mathrm{P}$-value $=0.00000$, RMSEA $=0.078$

Figure 2: The SBS' second order path diagram

\section{Criterion-Related Validity}

The scale's first criterion-related validity study was carried out by investigating the correlations between the data obtained from a sample of 30 university students and the SBS and SAS scores (See Table 2). Positive significant correlation values were between 0.77 and 0.87 with the SBS total scores and the SAS total and subscale scores $(\mathrm{p}<.05)$. The correlation values were computed to be between 0.73 and 0.80 in the positive direction between the SBS-EE and the SAS total and subscale scores $(\mathrm{p}<.05)$. The correlation values of the SBS-SC, SBS-AS, SBS-MM, SBS- 
S, and SBS-SCon subscale scores with the SAS total and other subscale scores were similar between 0.59 and 0.79 in the positive direction $(\mathrm{p}<.05)$.

Table 2: Correlation values of the SBS and SAS.

\begin{tabular}{llllllll}
\hline Variables & SBS-EE & SBS-SC & SBS-AS & SBS-MM & SBS-S & SBS-SCON & SBS \\
\hline SAS-PES & $.73^{* *}$ & $.73^{* *}$ & $.78^{* *}$ & $.77^{* *}$ & $.71^{* *}$ & $.59^{* *}$ & $.83^{* *}$ \\
SAS-NEP & $.74^{* *}$ & $.61^{* *}$ & $.64^{* *}$ & $.60^{* *}$ & $.76^{* *}$ & $.69^{* *}$ & $.77^{* *}$ \\
SAS & $.80^{* *}$ & $.74 * *$ & $.79 * *$ & $.76^{* *}$ & $.79^{* *}$ & $.69^{* *}$ & $.87 * *$ \\
\hline
\end{tabular}

$* \mathrm{p}<.05, * * \mathrm{p}<.01$

SBS: Selfitis Behavior Scale, SBS-EE: Environmental Enhancement, SBS-SC: Social

Competition, SBS-AS: Attention Seeking, SBS-MM: Mood Modification, SBS-S: Self-

Confidence, SBS-SCON: Subjective Conformity, SAS: Selfie Attitude Scale, SAS-PES: Positive

Experiences to Selfie, SAS-NEP: Negative Experiences on Prevention.

The other criterion-related validity research of the SBS was conducted with the sample in which the CFA was carried out. In the mentioned research, the selfie-taking frequency ofuniversity students was selected as a criterion. The comparison of these participants' arithmetic means of the scores was made by naming individuals who took selfies once a day at most "those taking fewer selfies" and individuals who took selfies twice a day and more "those taking more selfies" (See Table 3). Accordingly, a statistically significant difference was revealed between theSBS total and subscale scores' arithmetic means of university students taking more selfies and taking fewer selfies in favor of university students taking more selfies $(\mathrm{p}<.05)$.

Table 3: The findings of the t-test of groups who took more selfies and who took fewer selfies

\begin{tabular}{llllll}
\hline & Groups & & $\overline{\mathbf{x}}$ & Sd & $\mathrm{t}$ \\
\hline SBS-EE & Fewer & 51 & 4.73 & 1.50 & $-4.10^{*}$ \\
& More & 20 & 6.75 & 1.20 & \\
\hline SBS-SC & Fewer & 51 & 4.78 & 1.35 & $-4.56^{*}$ \\
& More & 20 & 6.85 & 1.84 & \\
\hline SBS-AS & Fewer & 51 & 4.67 & 1.86 & $-5.47^{*}$ \\
& More & 20 & 7.30 & 1.72 & \\
\hline SBS-MM & Fewer & 51 & 5.16 & 1.71 & $-6.36^{*}$ \\
& More & 20 & 8.25 & 2.15 & \\
\hline SBS-S & Fewer & 51 & 3.75 & 1.53 & $-2.15^{*}$ \\
& More & 20 & 4.60 & 1.43 & \\
\hline SBS-SCON & Fewer & 51 & 3.61 & 1.52 & $-4.02^{*}$ \\
& More & 20 & 5.20 & 1.44 & \\
\hline SBS & Fewer & 51 & 26.69 & 8.11 & $-5.63^{*}$ \\
& More & 20 & 38.95 & 8.63 & \\
\hline
\end{tabular}

$* \mathrm{p}<.05$

SBS: Selfitis Behavior Scale, SBS-EE: Environmental Enhancement, SBS-SC: Social Competition, SBS-AS: Attention Seeking, SBS-MM: Mood Modification, SBS-S: SelfConfidence, SBS-SCON: Subjective Conformity 


\section{Reliability Analysis}

The internal consistency coefficient $(\alpha)$ of the total score computed for the 20 items of the scale was $.92(\mathrm{~N}=246)$. This value was calculated to be .78 for the SBS-EE, .68 for the SBS-SC, .72 for the SBS-AS, .84 for the SBS-MM, .82 for the SBS-S, and .70 for the SBS-SCon $(\mathrm{p}<.05)$. To determine the SBS test-retest reliability, the correlation value between the total scores of the scale implemented on 30 university students two times at intervals of four weeks was .77. (p < .05). The SBS-SC correlation coefficients were found to be .70 for the SBS-EE, .60 for the SBS$\mathrm{SC}, .82$ for the SBS-AS, .80 for the SBS-MM, .61 for the SBS-S, and .61 for the SBS-SCon ( $<$ < $.05)$.

\section{Item Analysis Results}

In the item analysis, the item-total score correlation was investigated, and the end groups were compared $(\mathrm{N}=246)$. The correlation values between the university students' scores acquired from every item of the scale and the subscale corrected total scores were computed, and the values changed in the range of $.55-.70$ for the SBS-EE, in the range of $.44-.57$ for the SBS-SC, in the range of .48 - .60 for the SBS-AS, in the range of .68 - .74 for the SBS-MM, in the range of .60 .76 for the SBS-S, and in the range of $.47-.62$ for the SCS-SCon $(p<.05)$. While comparing the end groups, the scores of university students acquired from the scale were listed from large to small, and the upper and lower $27 \%$ groups $(\mathrm{N}=134)$ were taken, and the comparison of the arithmetic means of the scores acquired from every scale item by the mentioned groups was made. The analysis demonstrated that the t-values computed for all scale items varied between 4.69 and $16.25(\mathrm{p}<.05)$. It was determined that the participants who scored higher from the total of the scale had higher mean scores in all items compared to the participants who scored lower.

\section{Discussion}

In this study, which aimed to adapt the scale to measure the selfitis behavior of university students in Turkey, the validity and reliability measures of the SBS were performed. When carrying out the study, the Selfitis Behavior Scale was translated to Turkish, and the langue validity was ensured. Afterward, CFA was conducted to test the six-factor structure of the Selfitis Behavior Scale, and accordingly, the scale's fit indices were revealed to be at the good and excellent levels. The second-order CFA results showed that the scores of the SBS subscales predicted the SBS total score. However, the AGFI value was below the acceptable limits. There is an explanation for this result in the literature that the sample size influences the AGFI values (Cokluk, Sekercioglu, and Buyukozturk, 2016; Karagoz, 2016; Meydan and Sesen, 2015; Secer, 2015). Although the critical $\mathrm{N}$ is 131.96 in this study, the small sample size (N: 246) may be responsible for this result. Thus, in the assessment of the results, particularly in a case of a small sample, it is beneficial to assess all the fit indices together by considering the CFI, NFI, and NNFI values working very well (Celik and Yilmaz, 2013; Cokluk, Sekercioglu, and Buyukozturk, 2016; Karagoz, 2016; Meydan and Sesen, 2015; Secer, 2015). Based on this information in the literature, the study's findings may be regarded as evidence of the scale's construct validity. Consequently, this result shows us that the SBS consists of a simple and stable structure with six factors.

Moreover, criterion-related validity studies examined the SBS correlations and subscale scores to the SAS total and subscale scores. High scores from the SAS and its subscales indicate that the selfie attitude of college students is strong. Likewise, the increase in the SBS scores and its subscales showed that university students' selfitis behavior was strong. Therefore, a moderate and 
high positive correlation was expected between the scores from both scales. It is not surprising that a significant positive correlation was found between the SBS subscales and the SAS subscales. This result can be explained by the fact that environmental enhancement, social competition, attention-seeking, mood modification, self-confidence, and subjective conformity are closely related to both positive and negative experiences on prevention. Similar results of several studies in the literature show that people take and share selfies to make friends, develop self-confidence, and communicate (Cedillo and Ocampo, 2016; Charoensukmongkol, 2016; Edwards, 2017;Mullai, Macaj, and Kotherja, 2017; Nagalingam and Arumugam, 2015). Furthermore, a statistically significant difference between the mean scores of individuals who take "fewer" selfies and individuals who take "more" selfies shows that the SBS has a distinctive quality in terms of identifying university students' selfitis behavior. In other words, the Turkish version of the SBS can distinguish university students' selfitis behavior at the expected level and in the expected direction, which constitutes evidence for the validity of the SBS.

The internal consistency of the scale scores was computed, and discriminant reliability was evaluated. The fact that all the coefficients found for the total score and subscale scores concerning reliability were about .70 and higher than .70 demonstrates that the scale was highly consistent and time-sensitive with regard to measurement (Buyukozturk, 2011). There are three items in the SBSSC subscale. Because the internal consistency coefficient is related to the number of items included in the scale, it is thought that calculating the Cronbach's alpha value as 0.68 does not lead to a reliability problem. The item analysis findings were in line with the validity and reliability results of the measurement tool and supported the tool's psychometric properties.

\section{Recommendations}

When assessing the results acquired in the scale's construct validity research together, it is regarded that the tool has suitable construct validity. Nevertheless, since the GFI and AGFI values are below the expected level, particularly as a result of CFA, it is suggested to re-confirm the structure in question with similar samples. Moreover, because data collection was difficult due to the COVID-19 pandemic, the scale's reliability studies can be repeated on a larger sample in the future. In this study, the SBS was adapted to measure the selfitis behavior of university students. Other research can investigate the validity and reliability of the SBS in younger and older age groups.

\section{Conclusion:}

As a result of this study, it can be said that the SBS is a valid and reliable measurement tool capable of measuring the selfitis behavior of university students in Turkey by considering its limitations.

\section{Acknowledgments}

The current research was not funded by any organization.

\section{Compliance with Ethical Standards Conflict of Interest}

No conflict of interest is declared by the authors.

\section{Ethical Approval}

All procedures carried out in the present research, which included human participants, were 
in line with the ethical standards of the research ethics board of the university and with the 1975 Declaration of Helsinki. 
References:

Alblooshi, A. (2015). Self-esteem levels and selfies: The relationships between self-esteem levels and the number of selfies people take and post, and the uses and gratifications of taking and posting selfies. Master thesis, Middle Tennessee State University.

Alfailakawi, Y. (2018). What do selfies say about young Kuwaitis? Media Watch, 9(2), 167-181. Al-Menayes, J. (2015). Psychometric Properties and Validation of the Arabic Social Media Addiction Scale. Journal of Addiction. doi: 10.1155/2015/291743

Amurao, R. M. \& Castronuevo, E. (2016). Selfie behaviour and narcissism among selected females. The Bedan Journal of Psychology, 1, 24-33.

APA (n.d.). Selfitis. Retrieved 16.01.2021, from https://www.psychiatry.org/home/searchresults?k=selfie

APA. (2018). Too many selfies. Retrieved 16.01.2021, from https://www.psychiatry.org/newsroom/apa-blogs/apa-blog/2018/04/too-many-selfies

APA: Taking Selfies Is A Mental Disorder. (2014, 04 April). En Son Haber. Retrieved 16.01.2021, from https://www.ensonhaber.com/dunya/apa-selfie-cekmek-bir-ruhsal-bozukluk-2014-04-04

Balakrishnan, J., \& Griffiths, M. D. (2017). An Exploratory Study of "Selfitis" and the Development of the Selfitis Behavior Scale. International Journal of Mental Health Addiction 36(1), 3-6. doi: 10.1007/s11469-017-9844-x.

Boursier, V., Gioia, F., \& Griffiths, M. D. (2020a). Do Selfie-expectancies and Social Appearance Anxiety Predict Adolescents' Problematic Social Media Use? Computers in Human Behavior, 110. doi: 10.1016/j.chb.2020.106395

Boursier, V., Gioia, F., \& Griffiths, M. D. (2020b). Selfie-engagement on Social Media: Pathological Narcissism, Positive Expectation, and Body Objectification-Which is More Influential? Addictive Behaviors Reports, 11. doi: 10.1016/j.abrep.2020.100263

Buyukozturk, S. (2011). Handbook of data analysis for the social sciences, Ankara, Turkey.

Cedillo, M. J., \& Ocampo, R. (2016). Levels of Self-Monitoring, Self-Expression and Selfie Behavior Among Selected Filipino Youth. The Bedan Journal of Psychology 1, 45-52.

Celik, H. E., \& Yilmaz, V. (2013). Structural equality modeling with LISREL 9.1, Ankara, Turkey. Charoensukmongkol, P. (2016). Exploring Personal Characteristics Associated with Selfie-Liking. Cyberpsychology: Journal of Psychosocial Research and Cyberspace 10. doi: 10.5817/CP20162-7.

Ciplak, E., \& Cam, S. (2019). The development of the Selfie Attitude Scale: A validity and reliability study. European Journal of Education Studies, 6(8), 240-255.

Cokluk, O., Sekercioglu, G., \& Buyukozturk, S. (2016). Multivariate statistics for the social sciences: SPSS and LISREL applications, Ankara, Turkey.

Dokur, M., Petekkaya, E., \& Karadag, M. (2018). Media-based clinical research on selfie-related injuries and deaths. Turkish Journal of Trauma and Emergency Surgery, 24(2), 129-135.

Edwards, F. (2017). An Investigation of Attention-Seeking Behavior Through Social Media Post Framing. Athens Journal of Mass Media and Communications 3(1), 25-44

Hingerton, H. (2016). Social media selfies: Exploring relationships between gender, narcissism, self-esteem, body image and problematic internet use. Dublin Business School.

Karagoz, Y. (2016). SPSS and AMOS 23 applied statistical analyses, Ankara, Turkey.

Marcial, D. V. (2015). What's on Your Mind? Measuring Self-Promotional and Anti-Social Behaviors on Facebook among Tertiary Students. Information Technologies and Learning Tools, 48, 199-208. 
Meydan, C. H., \& Sesen, H. (2015). Structural equality modeling: AMOS applications, Ankara, Turkey.

Mullai, E., Macaj, O., \& Kotherja, O. (2017). Selfie-Mania Influence on Adolescent Self-Esteem. Interdisciplinary Journal of Research and Development, 4, 95-100.

Nagalingam, S., \& Arumugam, B. (2015). Self-Impetus to Self Portraits. International Journal of Healthcare Sciences, 3, 223-224.

Nagalingam, S., Arumugam, B., \& Thenniz Preethy (2019). Selfie Addiction: The Predigious Selfportraits. International Journal of Research in Medical Sciences, 7(3), 694-698.

Nearly 260 people have died taking selfies since 2011, study says. (2018, 4 October). Daily Sabah. Retrieved 08.02.2021, from https://www.dailysabah.com/life/2018/10/04/nearly-260-peoplehave-died-taking-selfies-since-2011-study-says

Safna, H. M. F. (2017). Negative Impact of Selfies on Youth. International Journal of Computer Science and Information Technology Research, 5(3), 68-73.

Secer, I., 2015. Psychological test development and adaptation process: SPSS and LISREL applications, Ankara, Turkey.

Senft, T. M., \& Baym, N. K., (2015). What Does the Selfie Say? Investigating a Global Phenomenon. International Journal of Communication, 9, 1588-1606.

Solanki, A. P. S. (2017). Selfie Addiction Scale. 16th World Congress on Psychiatry and Psychological Syndromes April 24-25, Las Vegas, USA.

Tiggemann, M., Anderberg, I., \& Brown, Z. (2020). Uploading Your Best Self: Selfie Editing and Body Dissatisfaction. Body Image, 33, 175-182. doi: 10.1016/j.bodyim.2020.03.002

Vats, M. (2015). Selfie Syndrome: An Infectious Gift of IT to Health Care. Journal of Lung, Pulmonary and Respiratory Rese, 2, 1-2.

Zhang, W. (2017, 27 December). Obsessively taking selfies is now a real mental disorder called 'selfitis'. PetaPixel. Retrieved January 16, from https://petapixel.com/2017/12/27/obsessivelytaking-selfies-now-real-mental-disorder-called-selfitis/ 